\title{
MR defecography in ano-rectal dysfunction: a clinical-radiological correlation study
}

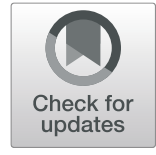

Samira Saraya ${ }^{1,4^{*}}$, Ahmed Awad ${ }^{2}$ and Rehab El EL Bakry ${ }^{3}$

\begin{abstract}
Background: The aim of this work is to assess the diagnostic accuracy of MR defecography in ano-rectal dysfunction [ARD] for proper treatment planning.

Results: MR defecography was done to 30 patients with ARD for detection of its functional and structural causes. Increased perineal descent was detected in $70 \%$ of cases, rectocele in $46.7 \%$, rectal intussusception in $40 \%$, cystocele in $26.7 \%$, uterine prolapse in $27.7 \%$, enterocele in $13.3 \%$, and paradoxical puborectalis contraction in $30 \%$. Conclusion: MR defecography is an essential diagnostic tool for optimum management of ano-rectal dysfunction patients.
\end{abstract}

Keywords: MR defecography, Ano-rectal dysfunction

\section{Background}

Constipation is a major health problem as it is considered one of the most common digestive complains [1]. Ano-rectal dysfunction [ARD] is an important sub-type of this disorder as it is involving almost $50 \%$ of constipated patients [2], it is defined as the urge to defecate but impaired ability to expel the fecal bolus [3], patients who suffer from this syndrome complain of excessive straining, impaired rectal evacuation, pain and/or bleeding after defecation, and sometimes the need of manually assisted defecation [4].

Evaluation and treatment of those patients have been difficult as it needs assessment of the pelvic floor integrity and function in its three compartments: anterior containing urinary bladder, urethra, and prostate; middle containing vagina and uterus; and the posterior anorectal one [5]. As a result, many imaging modalities have been used for further characterization of pelvic floor abnormalities such as endoanal sonography and endoanal MRI [6] with the ability to detect anal sphincter complex

\footnotetext{
*Correspondence: semsaraya@yahoo.com

'Faculty of Medicine, Diagnostic and Intervention, Radiology Department,

Cairo University, Kasr Al-Ainy, Cairo, Egypt

${ }^{4}$ Diagnostic and Intervention Radiology Department, Cairo University

Hospitals, El-Manial, Cairo 11956, Egypt

Full list of author information is available at the end of the article
}

and its pathological changes in refined anatomical details, but both fail to assess pelvic floor function [7].

For many years, fluoroscopic defecography was used to evaluate different causes of ARD including paradoxcial puborectalis contraction, increased perineal descent, rectocele, enterocele, and rectal intussusception, but this modality has its draw backs, as it cannot detect pelvic floor soft tissues, its projectional nature along with the ionizing radiation hazards [8]. Recently MR defecography emerged as a perfect modality considering its multiplanar capability, superior temporal resolution, and excellent soft tissue contrast in evaluating pelvic organs and soft tissues supporting structures in addition to assessing the defecation process in dynamic way [9].

The aim of the study was to evaluate the benefits of MR defecography in patients with ano-rectal dysfunction and its addition to the diagnosis and hence better management and outcome.

\section{Methods \\ This prospective study included 30 patients with ano- rectal dysfunction, from May 2015 till October 2015, [12 males, 18 females, age range $20-77$ years, mean age 48.5 $\pm 15.7]$ and control group included 10 healthy adults having normal bowel habit [4 males and 6 females, age}


range 25-62 years; mean age $43.5 \pm 13.7]$. Inclusion criteria include adult patients with chronic constipation for at least 3 months fulfilling at least 2 of the following according to "Rome Diagnostic Criteria III" for functional constipation [10], less than 3 motions per week, straining, hard stools, sensation of incomplete evacuation, sensation of ano-rectal obstruction, and manual assistance needed for defecation. Exclusion criteria were patients with 2ry constipation due to bad dietary habits, structural cause; as colonic strictures, tumors or volvulus, systemic diseases including metabolic and endocrinal disorders as diabetes mellitus, hypothyroidism, hyperparathyroidism, pregnancy, hypokalemia, or hypercalcemia. Neurologic disorders as stroke, head injury, spinal injury, multiple sclerosis, or Parkinson disease. Also, Hirschsprung disease and connective tissue disorders as amyloidosis and scleroderma.

\section{Clinical assessment}

Clinical evaluation was done to all patients by detailed history taking and physical assessment of abdomen and anal examination. Colonoscopy was done to all patients to exclude any obstructing cause like stricture, tumor or polyp. Also, Colon transit time was done to exclude patients with colonic inertia. Medical treatment was given to patients with ano-rectal dysfunction for 3 months in the form of bulk forming laxatives, and the patients that responded to the medical treatment were excluded from the study.

MR defecography was done to all patients needing no patient preparation with the explanation of the procedure done to the patients prior to the procedure to ensure their cooperation throughout the scanning. Consent was taken from all the patients along with human ethics committee approval from the institutional review board of the private hospital where the study took place.

\section{Image acquisition}

MR defecography was performed on 1.5 Tesla closed MR scanner "MAGNETOM Avanto, Siemens, Germany, " using a body-array-surface coil. First, the patient was on the left lateral decubitus to insert $300 \mathrm{ml}$ ultrasound gel through a rectal tube then the examination was done while he/she was in the supine position with the hips and knee flexed, stimulating physiological defecation position. Initially static imaging was done to evaluate pelvic anatomical details by axial and coronal T2weighted turbo spin-echo sequence with the following parameters: TR/TE 4000/100, matrix size $256 \times 256$, FOV $25 \mathrm{~mm}-35 \mathrm{~mm}$ with RFOV $100 \%$, slice thickness 4 $\mathrm{mm}$, then dynamic imaging was performed using T2weighted multiphasic 2D steady-state free precession sequence [SSFP] in the mid-sagittal plane through the anal canal with the following parameters: TR/TE 5.3/2.4, matrix size $320 \times 220$, FOV $40 \mathrm{~mm}$, slice thickness 10 $\mathrm{ml}$; this sequence was running for 2 min while the patient was instructed to strain till defecation occurs, acquiring about 250 images [2 image/s] and was repeated for another $2 \mathrm{~min}$ if the patient failed to defecate.

\section{Image analysis}

Images were analyzed by two different radiologists [4year experience in reading MRD, and the findings were recorded by consensus of both] on a PACS workstation [SECTRA IDS7 Sweden]; first, static images were reviewed to detect any pelvic floor abnormality then dynamic mid-sagittal images were evaluated in the two phases: rest and defecation in cine loop mode.

Normally at rest, all the pelvic organs, namely urinary bladder base, vaginal vault, and peritoneal cavity [omental fat-small bowel-sigmoid colon] should be above the pubococcygeal line (PCL) which is the line joining the inferior border of the symphysis pubis and the last coccygeal joint. Also, at rest, the ano-rectal angle (ARA) which is formed between the posterior border of the rectum and the central axis of the anal canal is between 65 and $100^{\circ}$ with no noticeable differences between males and females [11]; in straining the ARA increases and the perineum descends, its landmark is ano-rectal junction (ARJ) and it is considered normal when caudal migration is less than $2 \mathrm{~cm}$ relative to the resting position (Fig. 1). During defecation as a result of relaxation of the puborectalis muscle and anal sphincter, rectum and anal canal are in alignment causing more widening of the ARA [12]. Increase of the ARA less than $15-20^{\circ}$ is considered abnormal [13].

Presence of organ descent was measured as the perpendicular distance of ARJ (rectal descent), bladder base (cystocele), vaginal vault (uterine prolapse), and omental fat-small bowel-sigmoid colon (enterocele) below PCL [14]. Its grading was as follows: mild $2-<3 \mathrm{~cm}$, moder-

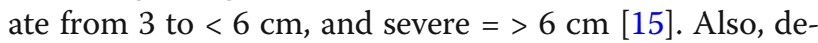
tection of associated findings, like rectocele, rectal intussusception, and paradoxical puborectalis, was documented. Rectocele which is defined as anterior rectal wall protrusion beyond the rectal wall during defecation, and it is graded as follows: mild $(<2 \mathrm{~cm})$, moderate $(2-4$ $\mathrm{cm})$, and large $(>4 \mathrm{~cm})$ [4]. Rectal intussusception which is internal invagination of the rectal wall, and it is classified according to the location into intra-rectal, intraanal, and according to thickness into mucosal or full thickness [16]. Paradoxical puborectalis is detected when there is failure of puborectalis muscle to relax during defecation with an increase of the ARA less than $15-20^{\circ}$ or even decrease [11].

\section{Statistical analysis}

IBM SPSS statistics (V. 25.0, IBM Corp., USA, 20172018) was used for data analysis. Data were expressed as 

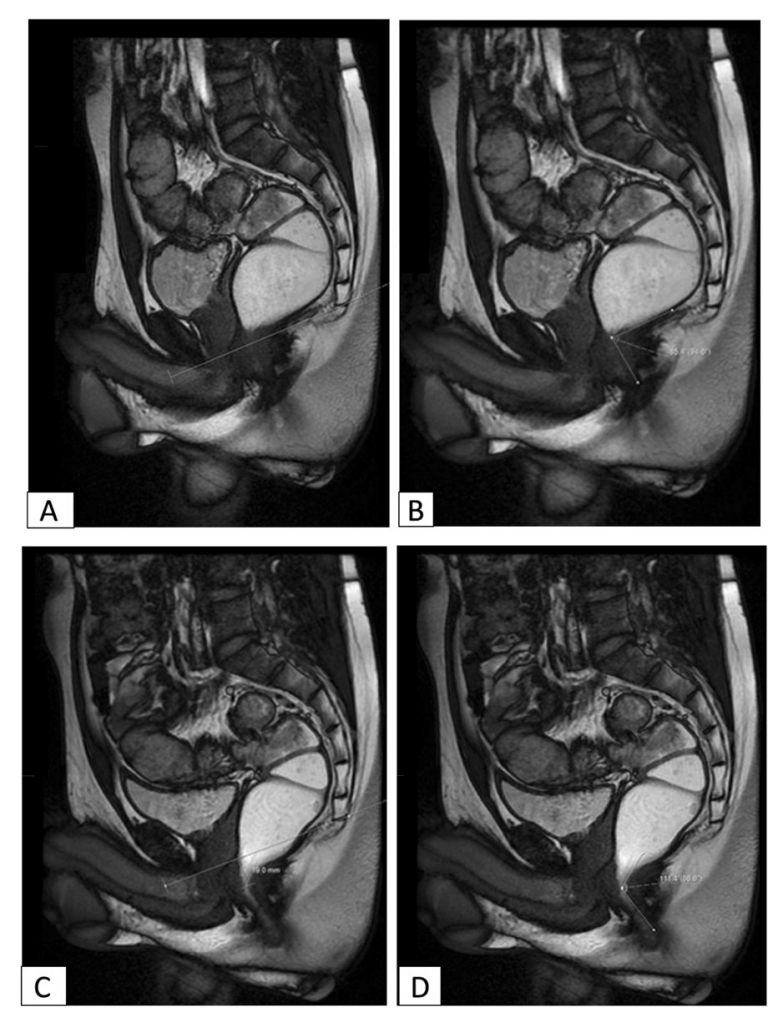

Fig. 1 Mid-sagittal SSFP obtained $(\mathbf{a}, \mathbf{b})$ at rest and $(\mathbf{c}, \mathbf{d})$ during defecation showing at rest rectum and bladder above the $P C L$ and ano-rectal angle measuring $85^{\circ}, \mathbf{c}$, $\mathbf{d}$ during defecation showing descent of ano-rectal junction $1.9 \mathrm{~cm}$ below the PCL [normal up to $2 \mathrm{~cm}$ ] and increase in ano-rectal angle above $20^{\circ}$ to be $111^{\circ}$

mean $\pm \mathrm{SD}$ for quantitative parametric measures in addition to both number and percentage for categorized data. Comparison between two dependent groups [clinical findings and MRD results] for parametric data using $Z$ test was used. The probability of error at 0.05 was considered significant, while at 0.01 and 0.001 are highly significant.

\section{Results}

Fifty-nine cases complaining of constipation were evaluated, 18 cases responded to the medical treatment, and hence were excluded from the study, rest of the cases [41 cases] underwent colonoscopy, 3 cases were excluded due to presence of colonic mechanical obstruction ( 2 cases of benign strictures due to diverticulosis and 1 case of malignant mass) with the remaining 38 cases underwent colonic transit time excluding 4 more cases of colonic inertia with the rest of the 34 cases showed outlet obstruction pattern for whom MR defecography was done, and 4 cases were excluded due to inability to perform defecation during the examination.

Clinical assessment showed 10 cases of rectal descent and prolapse (33.3\%) [6 cases were females and 4 cases were males], 12 cases of rectocele (40\%) [10 cases were females and 2 cases were males], 4 cases of rectal intussusception (13.3\%) [ 1 case was female and 3 cases were males], and 5 cases of cystocele (16.6\%); all were in the female population. Two cases of uterine prolapse $(11.1 \%$ of female population) and 3 cases of paradoxical puborectalis $(10 \%)$; all in the male population with no enterocele detected clinically.

By MR defecography, rectal descent was detected in 21 cases (70\%): 7 cases (33.3\%) were severe [6 cases were females and 1 case was male] as seen in (Figs. 2, 3, and 4) and 14 cases $(66.6 \%)$ were moderate [ 7 cases were females and 7 cases were males]. Fourteen cases of rectocele were observed (46.7\%), 3 cases were large (10\%); all were females (Fig. 3). Eleven cases were moderate (36.6\%) [8 cases were females and 3 cases were males] (Fig. 2). Twelve cases of rectal intussusception (40\%); all were intra-rectal. Four cases (13.3\%) were full thickness [ 1 case was female and 3 cases were males] (Figs. 3 and 4). Eight cases $(26.6 \%)$ were mucosal $[2$ cases were females and 6 cases were males] (Fig. 2). Cystocele was seen in eight cases (26.7\%): five cases moderate (16.7\%) (Fig. 2), and three cases mild (Fig. 3) (10\%); all were females showing statistically high significance than males with $P$ value 0.002. Uterine prolapse was seen in five cases $(27.7 \%$ of female cases): three cases were moderate and two cases were mild. Four cases (13.3\%) showed enterocele one was severe, and it was a female (Fig. 3); three were moderate
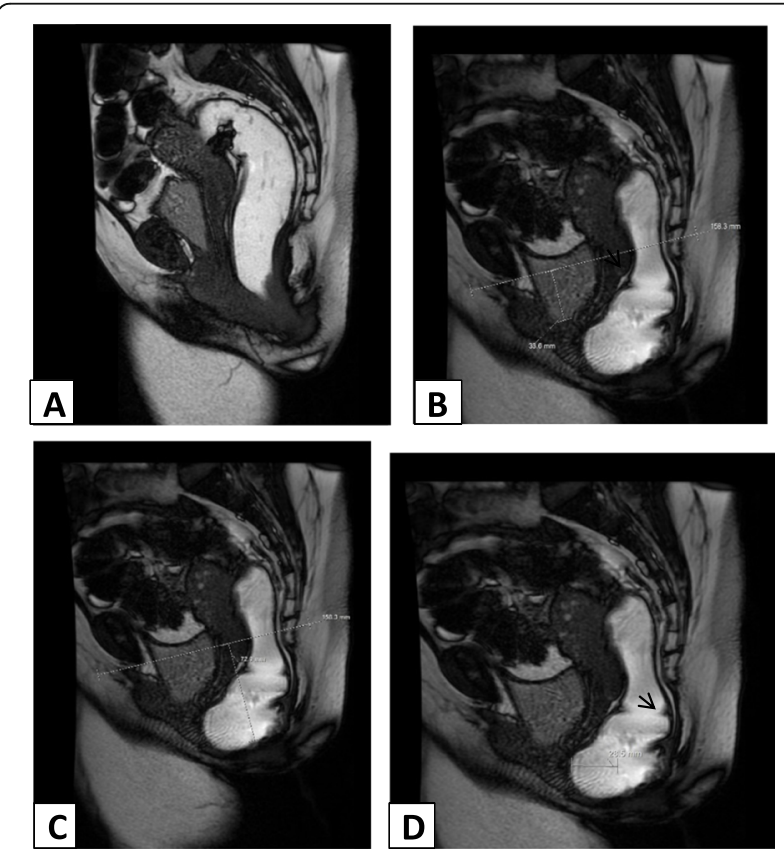

Fig. 2 Mid-sagittal SSFP obtained (a) at rest and (b-d) during defecation showing moderate cystocele $(3.3 \mathrm{~cm})$, severe rectal descent $(7.2 \mathrm{~cm})$, and moderate anterior rectocele $(2.6 \mathrm{~cm})$ with evidence of mucosal intussusception [arrow] 

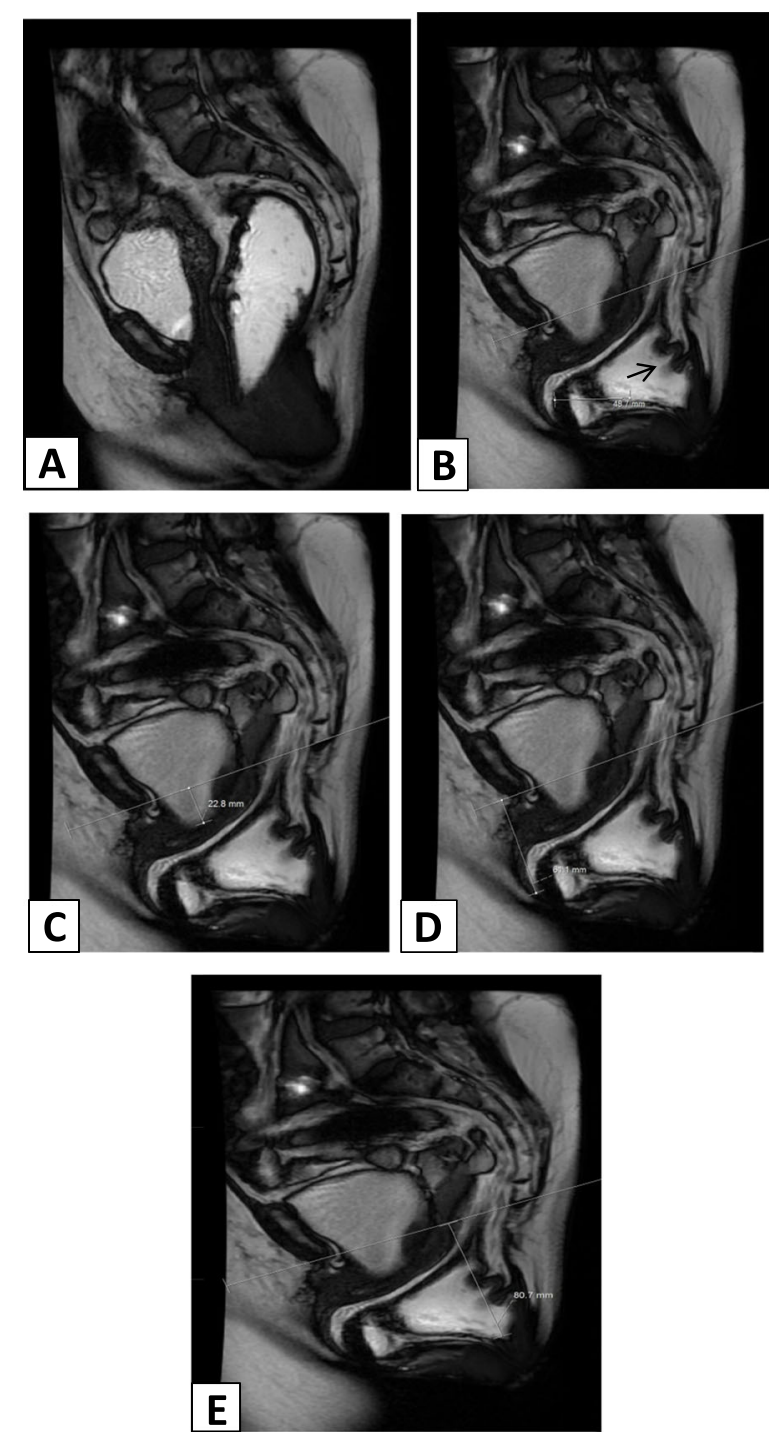

Fig. 3 Mid-sagittal SSFP obtained (a) at rest and (b-e) during defecation showing large anterior rectocele $(4.8 \mathrm{~cm})$, mild cystocele $(2.2 \mathrm{~cm})$, severe both enterocele $(6 \mathrm{~cm})$, and rectal descent $(8 \mathrm{~cm})$ with evidence of full-thickness intussusception [arrow]

[two cases were females and one case was male] (Fig. 4). Failure of puborectalis to relax during defecation was detected in nine cases (30\%) [two cases were females and seven cases were males], three cases with no other abnormality detected; all were males (Figs. 5 and 6). The rest six cases were four males and two females; all showed moderate rectal descent along with paradoxical puborectalis. Paradoxcial contraction of the muscle was seen in 6 cases (Figs. 5 and 6) while 3 cases showed increase in ARA angle $\leq 10^{\circ}$ (Fig. 7).

MR defecography showed statistically significant difference over clinical findings in detecting rectal descent, rectal intussusception, enterocele, and paradoxical puborectalis with no significant difference in detecting
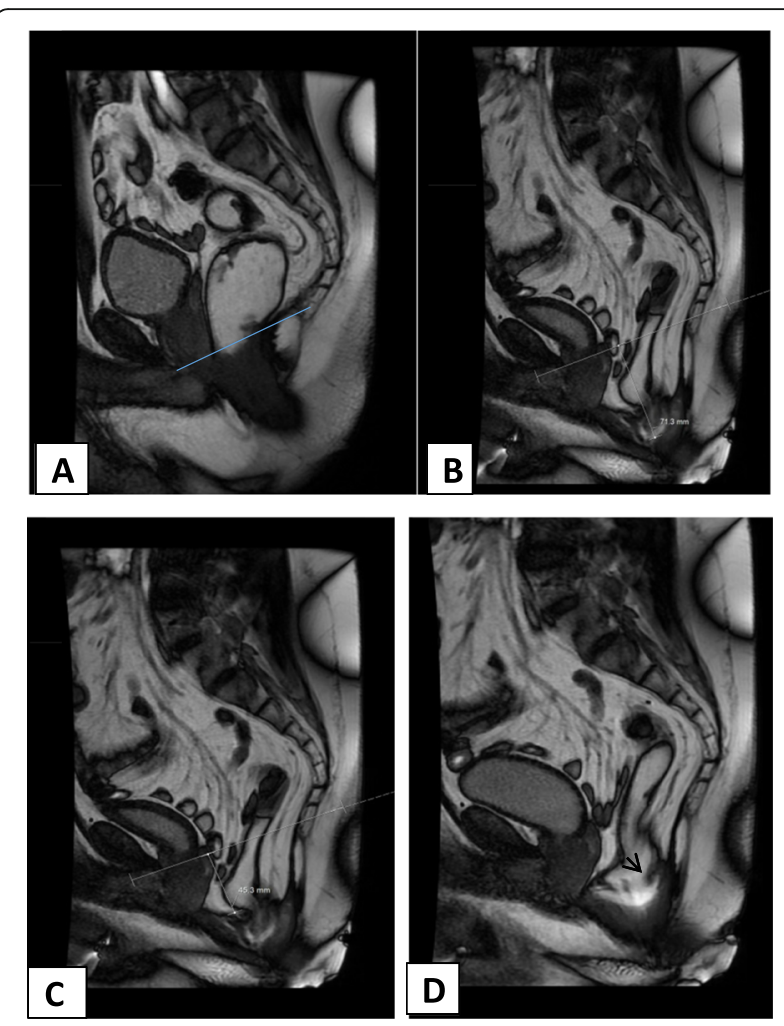

Fig. 4 Mid-sagittal SSFP obtained (a) at rest and (b-d) during defecation showing severe rectal descent $(7 \mathrm{~cm})$, moderate enterocele $(4.5 \mathrm{~cm})$ with evidence of full-thickness intussusception [arrow]

rectocele, cystocele, and uterine prolapse (Table 1). Both clinical assessment and MRD findings show predominance of the structural causes of ano-rectal dysfunction in females while functional one as in paradoxical puborectalis was predominant in males (Tables 2 and 3 ).

\section{Discussion}

Ano-rectal dysfunction (ARD) is of complex etiology requiring a multidisciplinary approach to assess the pelvic floor anatomy and function is its three compartments [17]; mostly, it is treated medically but nearly $20 \%$ of cases need surgery, and each surgery should be tailored according to the precise cause of ARD to obtain optimal results and to decrease both complications and recurrence [18].

Paradoxical puborectalis contraction is one of the commonest causes of functional constipation [19] where the puborectalis muscle fails to relax or even contracts during defecation causing no appreciable increase or even decrease in ARA resulting in ARD [20]. The etiology of this condition is unclear [21], and its diagnosis depends on both physical examination and ano-rectal physiologic testing, like ano-rectal manometry and anal/ pelvic floor electromyography (EMG), but both have certain limitations as voluntary contraction of puborectalis 

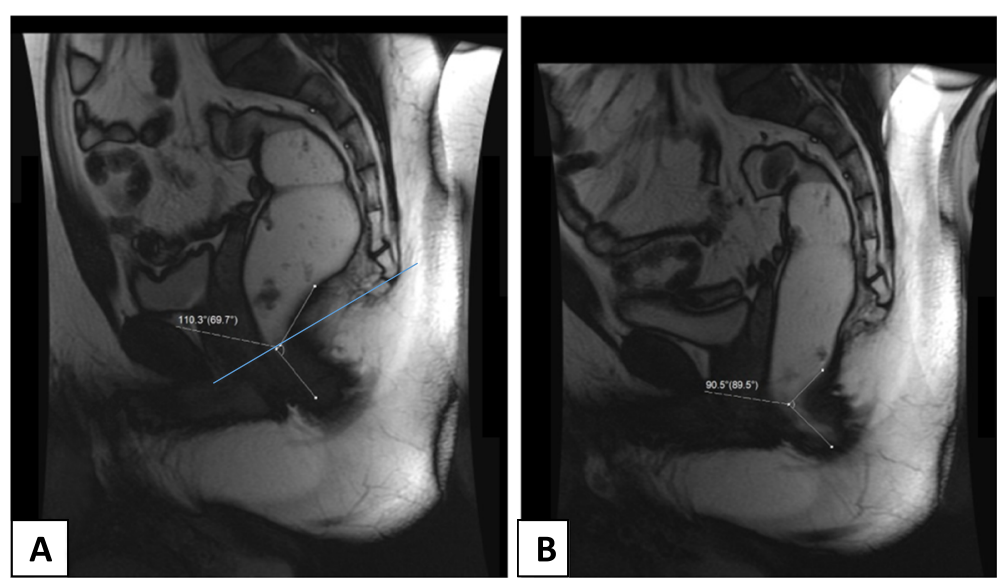

Fig. 5 Mid-sagittal SSFP obtained (a) at rest showing ano-rectal angle measuring $110^{\circ}$, b during defecation showing decrease in ano-rectal angle measuring $90^{\circ}$ suggestive of paradoxical puborectalis

muscle can occur due to anxiety to rectal examination itself, and the EMG has false-positive results caused by pain from the needle placement [22]; on the other hand, MR defecography can detect this pathological action of puborectalis muscle by measuring ARA during rest and during defecation and if there is less than $15-20^{\circ}$ widening or even decrease in the ARA detected in the latter phase diagnosis is made directing those patients to nonsurgical treatment. like biofeedback therapy [9]. In the current study, there was statistically significant difference between clinical assessment and MRD findings, with the capability of the latter to measure changes in ARA during defecation and this was in agreement with the findings of Nikjooy et al. [9] that showed abnormal ARA changes had sensitivity of $95 \%$, specificity of $92 \%$,
PPV of 95\%, and NPN of 92\% in differentiating patients with this disorder from normal subjects.

Structural causes of ARD include descending perineum syndrome which is abnormal pelvic floor descent during straining, and it is due to weakness of the pelvic floor muscles and ligaments from pudendal nerve injury as a result of obstetric trauma or chronic straining, it can occur in any of the three compartments of the pelvis; most of the times, more than one compartment is simultaneously involved [23]. In this study only $1 \mathrm{com}$ partment involvement was detected in 17 cases (56.6\%), 2 compartments in 8 cases $(26.6 \%)$, and 3 compartments in 2 cases $(6.6 \%)$ (Table 4). The importance of this finding is directing the treatment plan to target more than one compartment to avoid recurrence of symptoms.
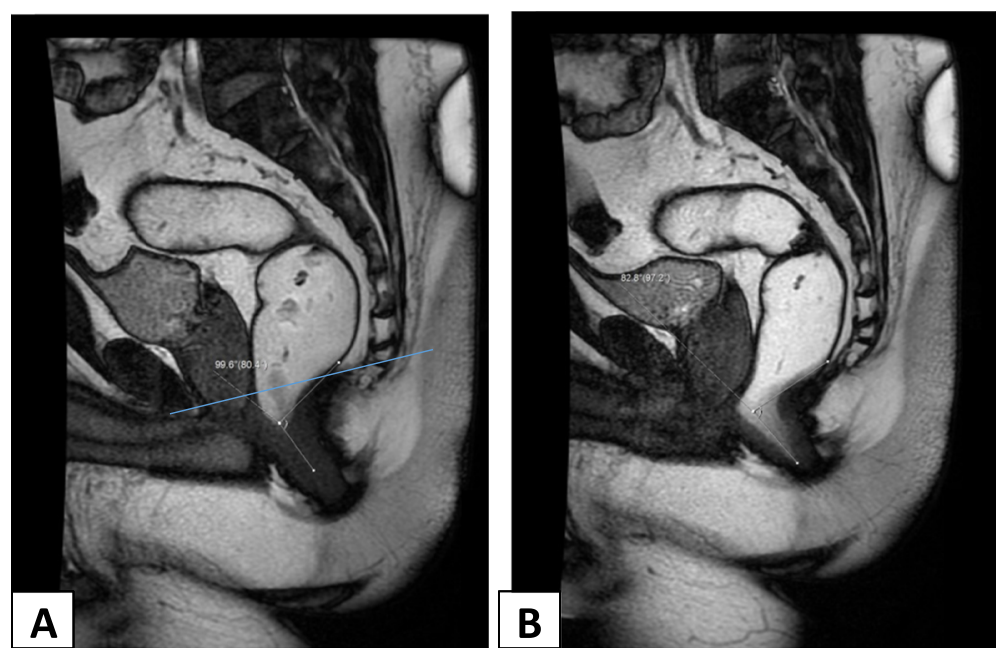

Fig. 6 Mid-sagittal SSFP obtained (a) at rest showing ano-rectal angle measuring $99^{\circ}$, b during defecation showing decrease in ano-rectal angle measuring $82^{\circ}$ suggestive of paradoxical puborectalis 

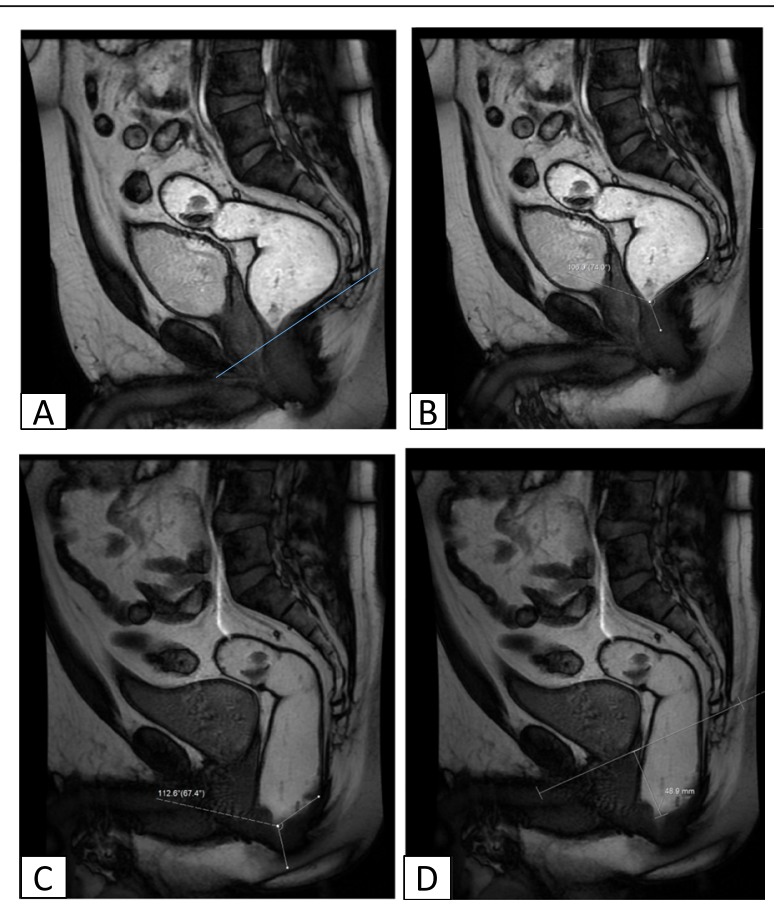

Fig. 7 Mid-sagital SSFP obtained $(\mathbf{a}, \mathbf{b})$ at rest and $(\mathbf{c}, \mathbf{d})$ during defecation showing at rest ano-rectal angle measuring $106^{\circ}$, c during defecation there is minimal increase in ano-rectal angle measuring $112\left[<10^{\circ}\right]$ denoting failure of puborectalis to relax associated with (d) moderate rectal descent $4.8 \mathrm{~cm}$

Rectal descent was the most frequent finding in the current study representing $70 \%$, which was in agreement with Rentsch et al. [24] findings being $60 \%$ and ElNashar et al. [25] being $65 \%$ and were more in females than males with no statistically significant difference, and this was in accordance with the results of Savoye et al. [26].

The second most frequent finding was anterior rectocele representing $46.7 \%$, and it was more frequent in females $(78.5 \%)$ with the large ones $[>4 \mathrm{~cm}$ ] were only detected in females; this result was similar to most of

Table 1 Comparison between clinical findings and MRD findings

\begin{tabular}{|c|c|c|c|c|c|c|c|}
\hline & $\begin{array}{l}\text { Clinical } \\
\text { no. }\end{array}$ & $\begin{array}{l}\text { Clinical } \\
\%\end{array}$ & $\begin{array}{l}\text { MRD } \\
\text { no. }\end{array}$ & $\begin{array}{l}\text { MRD } \\
\%\end{array}$ & $Z$ test & $P$ value & Sig. \\
\hline Rectal descent & 10 & 33.3 & 21 & 70 & 2.841 & $<0.01$ & $\overline{\mathrm{HS}}$ \\
\hline Rectocele & 12 & 40 & 14 & 46.7 & 0.521 & $>0.05$ & NS \\
\hline $\begin{array}{l}\text { Rectal } \\
\text { intussusception }\end{array}$ & 4 & 13.3 & 12 & 40 & 2.335 & $<0.01$ & $\mathrm{HS}$ \\
\hline Cystocele & 5 & 16.6 & 8 & 26.7 & 0.940 & $>0.05$ & NS \\
\hline Uterine prolapse & 2 & 11.1 & 5 & 35.7 & 1.3 & $>0.05$ & NS \\
\hline Enterocele & 0 & 0 & 4 & 13.3 & 2.072 & $<0.05$ & $S$ \\
\hline $\begin{array}{l}\text { Paradoxical } \\
\text { puborectalis }\end{array}$ & 3 & 10 & 9 & 30 & 2.322 & $<0.01$ & $\mathrm{HS}$ \\
\hline
\end{tabular}

HS highly significant, S significant, NS non-significant
Table 2 Comparison between male and female clinical findings

\begin{tabular}{llll}
\hline & Male & Female & Total \\
\hline Rectal descent & 4 & 6 & 10 \\
Rectocele & 2 & 10 & 12 \\
Rectal intussusception & 3 & 1 & 4 \\
Cystocele & 0 & 5 & 5 \\
Uterine prolapse & 0 & 2 & 2 \\
Enterocele & 0 & 0 & 0 \\
Paradoxical puborectalis & 3 & 0 & 3 \\
\hline
\end{tabular}

the studies evaluating rectocele showing significantly higher percentage among females [27], with some studies like Dietz and Clarke [28] and Carter and Gabel [29] included only female population. In spite that rectocele can be detected clinically and in the current study, there was no statistically significant difference between the clinical findings and MRD findings, but better evaluation of the rectocele size, emptying and presence of associated findings can only be achieved by imaging [5].

Enterocele was found in 4 patients $13.3 \%$, being more predominate in female population with none could be detected clinically showing superiority of MRD in detecting it, which is important prior to surgical treatment to avoid bowel injury [4]. Rectal intussusception was detected in twelve cases (40\%), all were intra-rectal, four cases $(13.3 \%)$ were full thickness [One case was female and three cases were males], eight cases (26.6\%) mucosal [Two cases were females and six cases were males]. Cystocele represented $26.7 \%$ were only detected in females as it is due to weakness of the pubo-cervical fascia from obstetric trauma. Uterine prolapse was seen in 5/ 18 cases presenting $27.7 \%$.

The current study showed that the additional data obtained from MRD over the clinical evaluation play an important role in adjusting the treatment plan regarding non-surgical management as starting by biofeedback and physiotherapy in cases involving paradoxical puborectalis with surgical treatment decision was adjusted after

Table 3 Comparison between male and female MR findings

\begin{tabular}{llll}
\hline & Male & Female & Total \\
\hline Rectal descent & 8 & 13 & 21 \\
Rectocele & 3 & 11 & 14 \\
Rectal intussusception & 9 & 3 & 12 \\
Cystocele & 0 & 8 & 8 \\
Uterine prolapse & 0 & 5 & 5 \\
Enterocele & 1 & 3 & 4 \\
Paradoxical puborectalis & 7 & 2 & 9 \\
\hline
\end{tabular}


Table 4 Number of pelvic compartment affected by MRD

\begin{tabular}{lll}
\hline No. of compartment affection & No. of cases & $\%$ \\
\hline One & 17 & 56.6 \\
Two & 8 & 26.6 \\
Three & 2 & 6.6 \\
None & 3 & 10 \\
\hline
\end{tabular}

diagnosing coexisted pathology by MRD from perineal operation to abdominal/combined operation after diagnosing multiple pathologies in the same compartment or different compartments.

\section{Conclusion}

MR defecography is essential in the work up of patients complaining of ano-rectal dysfunction by providing valuable information to the physician aiming for proper management decreasing both complications and recurrence.

\section{Abbreviations}

ARD: Ano-rectal dysfunction; MR: Magnetic resonance; MRI: Magnetic resonance imaging; SSFP: Steady-state free precession sequence; MRD: Magnetic resonance defecography; PCL: Pubococcygeal line; ARA: Anorectal angle; ARJ: Ano-rectal junction; PPV: Positive predictive value; NPV: Negative predictive value

\section{Acknowledgements}

Not applicable.

\section{Authors' contributions}

SS, AA, and REB contributed to this work. SS and AA designed the research. $S S, A A$, and REB performed the research. SS and REB analyzed the data. SS, $A A$, and REB wrote the paper. All authors have read and approved the manuscript.

\section{Funding}

The study has no funding from any resource.

\section{Availability of data and materials}

The datasets used and/or analyzed during the current study are available from the corresponding author on reasonable request.

\section{Ethics approval and consent to participate}

This study was approved by the research ethic committee of the Radiology Department of the Faculty of Medicine at Cairo University on 03/01/2015; reference number of approval: 813-2015. All patients included in this study gave a written informed consent to participate in this research.

\section{Consent for publication}

All patients included in this study gave a written informed consent to participate in this research.

\section{Competing interests}

The authors declare that they have no competing interests.

\section{Author details}

${ }^{1}$ Faculty of Medicine, Diagnostic and Intervention, Radiology Department, Cairo University, Kasr Al-Ainy, Cairo, Egypt. ${ }^{2}$ Faculty of Medicine, General Surgery Department, Ain Shams University, El Demerdash, Cairo, Egypt. ${ }^{3}$ Faculty of Medicine, Diagnostic and Intervention Radiology Department, Ain Shams University, El Demerdash, Cairo, Egypt. ${ }^{4}$ Diagnostic and Intervention Radiology Department, Cairo University Hospitals, El-Manial, Cairo 11956, Egypt.
Received: 10 June 2020 Accepted: 11 August 2020

Published online: 28 August 2020

\section{References}

1. Higgins PD, Johanson JF (2004) Epidemiology of constipation in North America: a systematic review. Am J Gastroenterol 99(4):750-759

2. Bolog N, Weishaupt D (2005) Dynamic MR Imaging of Outlet Obstruction. Romanian Journal of Gastroenterology 14(3):293-302

3. National Institute for Health and Clinical Excellence. Stapled trans-anal rectal resection for obstructed defecation syndrome. NICE Interventional Procedure Guidance (IPG 351) Issued June 2010. Available from: http:// www.nice.org.uk. [Last accessed on 2014 June 20].

4. Thapar RB, Patankar RV, Kamat RD et al (2015) MR defecography for obstructed defecation syndrome. Indian Journal of Radiology and Imaging 25(1):25-30

5. El Shazly WG, El Nekady A, Hassan H (2010) Role of dynamic magnetic resonance imaging in management of obstructed defecation case series. International Journal of Surgery 8:274-282

6. Podzemny V, Pescatori LC, Pescatori M (2015) Management of obstructed defecation. World J Gastroenterol 21(4):1053-1060

7. Dobben AC, Terra MP, Slors JF et al (2007) External anal sphincter defects in patients with fecal incontinence: comparison of endoanal MR imaging and endoanal US. Radiology 242:463-471

8. Flusberg M, Sahni VA, Erturk SM (2011) Dynamic MR defecography: assessment of the usefulness of the defecation phase. AJR 196:394-399

9. Nikjooy A, Maroufi N, Esmaeil Ebrahimi E et al (2016) Accurate differentiation of dyssynergic defecation patients from normal subjects based on abnormal anorectal angle in MR defecography. J Yoga Phy Ther 6(3):1-6

10. Chiarelli P (2008) Systematic review: the management of constipation using physical therapies including biofeedback. Australian New Zealand Continence J 14:6-13

11. Kim AY (2011) How to interpret a functional or motility test-defecography. J Neurogastroenterol Motil 17(4):416-420

12. Mortele KJ, Fairhurst J (2007) Dynamic MR defecography of the posterior compartment: Indications, techniques and MRI features. European Journal of Radiology 61:462-472

13. Azab IA, Nasef MA, Ibrahim AM (2014) Dynamic magnetic resonance imaging; reliability of assessment and correlation with clinical findings of pelvic organ prolapse. The Egyptian Journal of Radiology and Nuclear Medicine 45:1003-1010

14. Darwish HS, Zaytoun HA, Kamel HA et al (2014) Assessment of pelvic floor dysfunctions using dynamic magnetic resonance imaging. The Egyptian Journal of Radiology and Nuclear Medicine 45:225-229

15. Roos JE, Weishaupt D, Wildermuth $S$ et al (2002) Experience of 4 years with open MR defecography: pictorial review of anorectal anatomy and disease. Radiographics 22:817-832

16. Chiarioni G, Heymen S, Whitehead WE (2006) Biofeedback therapy for dyssynergic defecation. World J Gastroenterol 12(44):7069-7074

17. Colaiacomo MC, Masselli G, Polettini E et al (2009) Dynamic MR imaging of the pelvic floor: a pictorial review. Radiographics 29:1-42

18. Podzemny $V$, Pescatori LC, Pescatori M (2015) Mangment of obstructed defecation. World Journal of Gastroenterology. 21:1053-1060

19. Rao SS (2008) Dyssynergic defecation \& biofeedback therapy. Gastroenterol Clin North Am 37(3):569-586

20. Deveaux PJ, Galandiuk S (2006) Etiology of acquired colorectal disease: constipation, 2nd edn. Springer-Verlag, London, pp 15-24

21. Pucciani $F$ (2015) Descending perineum syndrome: new perspectives. Tech Coloproctol 19(8):443-448

22. Brown CG, Mohsen NS (2017) Evaluation of pelvic floor dysfunction with dynamic MRI. J Am Osteopath Coll Radiol 6(3):13-11

23. Landmann RG, Wexner SD (2008) Paradoxical puborectalis contraction and increased perineal descent. Clin Colon Rectal Surg 21:138-145

24. Rentsch M, Paetzel C, Lenhart M et al (2001) Dynamic magnetic resonance imaging defecography: a diagnostic alternative in the assessment of pelvic floor disorders in proctology. Dis Colon Rectum 44(7):999-1007

25. El-Nashar SA, Occhino JA, Trabuco E et al (2014) Descending perineum syndrome: a fresh look at an interesting and complex pelvic floor disorder. J Minimally Invasive Gynecol 21(2):S16-S17 
26. Savoye-Collet C, Savoye G, Koning E, Leroi AM, Dacher JN (2010) Gender influence on defecographic abnormalities in patients with posterior pelvic floor disorders. World J Gastroenterol 16(4):462-466

27. Ahmed EA, Shamseya AM, Mamdouh $\mathrm{HH}$ et al (2015) Study of the role of dynamic pelvic MRI defecography in evaluation of patients with chronic constipation. Int J Recent Adv Multidisciplinary Res 11(2):977-984

28. Dietz HP, Clarke B (2005) Prevalence of rectocele in young nulliparous women. Aust N Z J Obstet Gynaecol 45(5):391-394

29. Carter D, Gabel MB (2012) Rectocele--does the size matter? Int J Colorectal Dis 27(7):975-980

\section{Publisher's Note}

Springer Nature remains neutral with regard to jurisdictional claims in published maps and institutional affiliations.

\section{Submit your manuscript to a SpringerOpen ${ }^{\odot}$ journal and benefit from:}

- Convenient online submission

- Rigorous peer review

- Open access: articles freely available online

High visibility within the field

- Retaining the copyright to your article

Submit your next manuscript at $\boldsymbol{\nabla}$ springeropen.com 